\title{
Identifying Factors Influencing the Leadership Performance of Saudi's Healthcare Sector
}

\author{
Namshan A Algarni, McLaughlin Patrick, Al-Ashaab Ahmed and Rashid Hamad \\ Cranfield university, Cranfield, United Kingdom \\ Correspondence should be addressed to: Namshan A Algarni; n.a.algarni@cranfield.ac.uk
}

Received date: 6 September 2017; Accepted date: 24 November 2017; Published date: 9 February 2018

Academic Editor: Inga Hunter

Copyright (c) 2018. Namshan A Algarni, McLaughlin Patrick, Al-Ashaab Ahmed and Rashid Hamad. Distributed under Creative Commons CC-BY 4.0

\begin{abstract}
The purpose of this article is to identify the aspects that relate to performance level; including enablers and inhibitors that influence leadership performance in the healthcare sector of the Kingdom of Saudi Arabia (KSA). A grounded research methodology and an action research approach that was 'issue focused' were used to gain the perceptions of the participants from the organisational culture as empirical data. The overall trends observed in the collected data emphasize the important role of culture in shaping performance level. In addition, the domination of factors related to the national culture and Islamic values has appeared the greatest factor affecting leaders' decisions; it also forms their relations with subordinates as well as their commitment to the organization. Viewed through this study, the effect of culture aspects on the performance level in this important sector can be understood and new and integrated solutions to overcome potential negative outcomes. Because of the chosen research approach, the research results may lack generalisability. Therefore, researchers are encouraged to test the proposed propositions further. The paper discusses the implications of the study findings for healthcare sector managers in different levels. This paper fulfils an identified need to study how culture can influence workforce practices in healthcare organizations and to what extent can that affect the quality of services delivered to the patients.
\end{abstract}

Keywords: Healthcare sector, Saudi Arabia, culture, Leadership performance

Cite this Article as: Namshan A Algarni, McLaughlin Patrick, Al-Ashaab Ahmed and Rashid Hamad (2018)," Identifying Factors Influencing the Leadership Performance of Saudi's Healthcare Sector", The Journal of Organizational Management Studies, Vol. 2018 (2018), Article ID 683208, DOI: 10.5171/2018.683208 


\section{Introduction}

Saudi Arabia is a country in Western Asia covering an area of approximately 2,250,000 square kilometres (868,730 square miles) between the Arabian Gulf on the east and the Red Sea on the west (Alexander, 2011; AlRabeeah, 2003; Hamdan, 2005). In 2016, its population was approximately 32 million people, of which the population of Saudi nationals was 20.8 million people $(66.9 \%$ of the total population) with a $1.62 \%$ annual population growth, and a foreign population of 10.25 million, $(33.1 \%$ of the total population) (The Saudi General Authority For Statistics, 2017). The country was established in 1932 by King AbdulAziz ibn AbdulRahman Al Saud (Mellahi, 2007; Alexander, 2011). Arabic is the official language and Islam is the official religion (Alexander, 2011). According to Mellahi, (2007, p. 88) "Saudi Arabia is governed by an Islamic monarchy in which Islam makes up the civil, cultural, economic, legal, political and social fabric of the country". The Kingdom of Saudi Arabia has religious importance as the birthplace of Islam and the home to two of the holiest Muslim sites, the holy Mosque in Makkah and the Prophet Mohammad Mosque in Madinah (Dirani et al., 2017). This has made the country the primary otherworldly middle for Muslims the world over, with millions of travellers visiting Saudi Arabia each year (Abdulwahab, 2015).

In term of economics, the Kingdom of Saudi Arabia has the largest global oil reserves, containing $25 \%$ of the world's resources (Saleh and Otaibi, 2017; Aljaidi, 2010). The KSA represents one of the most significant markets in the region for both domestic and international investors (Al-Bosaily et al., 2017). It estimated that the population of Saudi Arabia will reach 39.8 million by 2025, and 54.7 million by 2050 (United Nations, 2003). This expected growth of the population will mean an increased demand for essential services and facilities, such as healthcare services (Alkhamis et al., 2017). This is in line with the new vision of the country. The momentum and pace of economic and social reforms have been fuelled by the Kingdom's Vision 2030 and its strategic goals (PWC - Middle East - Hala Kudwah, 2017).

\section{The Saudi healthcare system}

The initial health service infrastructure began to develop in 1925 when the first Public Health Department was established in Makkah in 1925 following a Royal decree from King Abdulaziz (Khaliq, 2012; AlRabeeah, 2003; Alharthi et al., 1999). This department was responsible for sponsoring and monitoring free healthcare for the population and pilgrims and establishing a number of hospitals and dispensaries (Almalki et al., 2011; Saleh and Otaibi, 2017). According to Khaliq (2012, p. 53) "the origins of the Saudi healthcare system can be traced to 1926 , with the establishment of a Health Directorate in Jeddah and the opening of Ajyad hospital in Mecca and Bab Shareef hospital in Jeddah". In 1951, the Saudi Ministry of Health was created (Khaliq, 2012).

Healthcare in Saudi Arabia is currently provided free of charge to all Saudi citizens and to expatriates working in the public sector, primarily through the Ministry of Health and augmented by other governmental health facilities (Walston et al. 2008; Al-Yousuf et al., 2002). KSA has a national healthcare system that provides health services through a number of governmental agencies: The Ministry of Health, the Ministry of National Guard, the Ministry of Defence and Aviation, and the Ministry of the Interior (Khaliq, 2012; Maseru et al. 1990). There is also a growing participation in the provision of healthcare (HC) services by the private sector (Alkhamis et al., 2017). The hospital bed capacity in the KSA in 2015 was 69,394; more than half of this $(58.7 \%)$ was under the Ministry of Health; other state agencies controlled 20.2 per cent; and 21.0per cent was in the private sector (Saudi General Authority Statistics, 
2016). According to a recent report produced by the Saudi Embassy in the USA (2017), Saudi Arabia is considered the largest market for medical equipment and healthcare products in the Middle East. This includes medical education, research, facilities, provision, and the healthcare value chain.

In the past few decades, health and health services have improved significantly in terms of quantity and quality (Saleh and Otaibi, 2017). Similarly, in 2006, the Saudi health services ranked $26^{\text {th }}$ out of 190 of the world's health systems (Alkhamis et al., 2017; WHO 2000).

As shown in Table 1, the number of hospitals and beds in the healthcare sectors of the KSA has gradually increased over the past five years.

\section{Table 1 : Total Hospital and Beds in the Saudi healthcare}

(Saudi General Authority Statistics, 2016)

\begin{tabular}{|c|c|c|c|c|c|c|c|c|c|c|}
\hline & \multicolumn{7}{|c|}{$\begin{array}{l}\text { otel Hospitals and Beds In the Kingdern by agency } \\
\qquad 2011-2015 .\end{array}$} & & & \\
\hline & \multicolumn{2}{|l|}{ | anla $\angle-1 i$} & \multirow{2}{*}{\multicolumn{2}{|c|}{2014}} & \multirow{2}{*}{\multicolumn{2}{|c|}{2013}} & & & & \\
\hline & \multicolumn{2}{|c|}{2015} & & & & & \multicolumn{2}{|c|}{2012} & \multicolumn{2}{|c|}{2011} \\
\hline & Eeds & Hospitals & Beds & Hospitals & Bods & Hospitals & Beds & Hospi:als & Bods & Hospitas \\
\hline MOII & 41297 & 274 & 40300 & 270 & 38970 & 260 & 35823 & 259 & 34450 & 251 \\
\hline Other governmental sectors & 11449 & 43 & 12032 & 42 & 11414 & 41 & 11043 & 39 & 10948 & 39 \\
\hline private sector & 16048 & 145 & 15005 & 141 & 14310 & 130 & 14165 & 137 & 13298 & 130 \\
\hline I otal & 69391 & 162 & $6 / 99 /$ & 103 & b15y4 & 115 & 61036 & 135 & 58696 & 120 \\
\hline & & 11.⿲丿丨 M & & & & & & & & \\
\hline
\end{tabular}

The healthcare sector of Saudi Arabia is currently working intensively on comprehensive development and modernisation in order to improve performance and deliver a better service (Albejaidi, 2010). According to Almalki et al.(2011, p. 792) "The national strategy for healthcare services is to be implemented by the ministry of health in cooperation with other healthcare providers and it will be supervised by the Council of Health Services". The time frame for this strategy is planned to be 20 years (Almalki et al., 2011). In addition, according to the Saudi transformation plans for the coming five years, the government intends to proceed with the construction of 56 new and 51 replacement hospitals and
750 primary health centres (Saudi Embassy in the USA, 2017).

Importantly, Yusuf (2014, p. 117) pointed out some challenges to the Saudi government saying, "the increasing population and health expenditures are forcing the government to come up with considerable changes in the healthcare system". Additionally, it is estimated that by 2020 , the total number of people aged 60 and above will be over 2.5 million (Yusuf, 2014; Alkhamis et al., 2017). This aging of the population will increase the demand for and expenditure on healthcare. In addition, in a previous study, Walston et al. (2008) indicated that factors that affect the service of this sector; the large percent of

Namshan A Algarni, McLaughlin Patrick, Al-Ashaab Ahmed and Rashid Hamad (2018), The Journal of Organizational Management Studies, DOI: 10.5171/2018.683208 
foreign workers and the high percentage of young people of the population.

Significantly, Al-Borie and Abdullah (2013) maintain that one of the challenges that healthcare in the KSA must combat is the current state of planning and development initiatives, which are top-down (imposed) and not bottom-up (agreed). They also emphasise that healthcare in the KSA must continually develop the professional skills of its workers so that they can deal with challenges they may encounter in the reforms. Hence, percentage of foreign workers and the high proportion of young people in the population. These factors and challenges affect the level of service, leading so far, to the failure of the government's plan to sustain the development of this important sector this can discredit the government and disappoints patients.

Factors found to be influencing healthcare services have been explored in several studies. For instance, Armit et al. (2015) suggest that health and social care services must be integrated in order to meet the needs of patients, service users and communities both efficiently and effectively. Healthcare has to be delivered by an interdependent network of organizations and this requires leaders to work together, spanning organizational boundaries both within and between organizations, prioritising overall patient care rather than the success of their component of it (Armit et al., 2015).

Significantly, National culture plays an important role to shape an individual's work ethic (Yousef, 2001). Previous studies in this context confirm that the significant impact of organisational culture on worker motivation and organisational performance is widely acknowledged (Franco et al, 2002). Schein (2004) argues that culture is a perceptual structure of underlying assumptions that have been discovered, developed, or improved by a given group as the group learns to cope with its challenges of external adaptation and internal integration.
Furthermore, culture has been defined to imply a set of shared, taken-for-granted implicit assumptions held by the members of an organisation, which determines the way that they perceive, think about and respond to things (Schein, 2004). This view is supported by Rees and Althakhri, (2008, p. 124) who write that the "Saudi Arabian culture is strongly affected by Islamic and tribalism systems".

\section{Methodology}

This study was exploratory and interpretive in nature as shown in Table 2. Hence, a grounded approach was used in order to capture the perceptions of the participants from the organisation (Glaser, Strauss and Strutzel, 1968). The interpretive paradigm and grounded theory were found to be useful for this study, in enabling the researcher to use individuals' perceptions and meanings in order to explore, explain and describe what was going on; they enabled the researcher to construct a theory that was grounded in the data collected (Corbin and Strauss, 2014). In other words, grounded theory facilitates the understanding of social reality, and lets the data tell their story (Corbin and Strauss, 2014). An appropriate method to gather aspects controlling performance in the field study was to use some issue (Sackmann, 1991) to encourage the participants to focus their attention on a specific action. A major advantage of this method as Sakmann (1991) claims, is that it enables both the surfacing of tacit components of culture and comparisons across individuals and research settings. This method helps researchers at this stage to understand the factors that influence the organisation's culture. Identifying those specific aspects that play the key role in a field study is essential for the subsequent research process. Data were gathered from multiple sources at various time points during research process. Throughout the iterative steps in data collection, theoretical sampling was followed in this study in order to determine a certain level of saturation. The data management and analysis tool selected was NVivo software. This qualitative 
data analysis package was used for the initial stages of coding and facilitated the coding and analytical processes (Yin, 1989). Given the innovations in software technology, electronic techniques of data coding are being employed more often to obtain rigor in dealing with such data (Saleh and Alabri, 2013). To ensure the trustworthiness of the findings and the accuracy of the coding, every response made, whether positive or negative, was considered (Corbin and Strauss, 1994).

Table 2 : Research methodology

\begin{tabular}{|l|l|l|l|}
\hline Paradigm & \multicolumn{2}{|l|}{ Interpretivist } \\
\hline $\begin{array}{l}\text { Research } \\
\text { Approach }\end{array}$ & Field Study & Focus Groups \\
\hline $\begin{array}{l}\text { Research } \\
\text { Strategy }\end{array}$ & Grounded Theory & Observation \\
\hline $\begin{array}{l}\text { Research } \\
\text { Methods }\end{array}$ & Interviews (Issue focus) & \\
\hline $\begin{array}{l}\text { Analytic } \\
\text { Framework }\end{array}$ & $\begin{array}{l}\text { Grounded Theory (Open Coding, Selective Coding, and Axial } \\
\text { Coding) - Textual Analysis }\end{array}$ \\
\hline
\end{tabular}

The fieldwork for this study was to 33 interviews as shown in Figure 1 below. Throughout the iterative steps in data collection, theoretical sampling was followed in this study in order to determine a certain level of saturation. Following guidelines from
Binder and Edwards, (2010, p. 241), the researcher continued to recruit and interview participants until the point at which no new data was produced that added new information or insights for constructing the theory.

Gender of Participants:

Levels Position of Participants:

Male 21

Executives level

5

Female 8

Managers

14

Employees

10

Figure 1: participants' demographic

Namshan A Algarni, McLaughlin Patrick, Al-Ashaab Ahmed and Rashid Hamad (2018), The Journal of Organizational Management Studies, DOI: 10.5171/2018.683208 
Face-to-face interviews took place between June and July 2015 as a first stage of data collection, lasting between 45 and 92 minutes each. The questions aimed to identify the factors that relate to performance level, as encouragers or inhibitors of performance improvement. The researcher designed and conducted a pilot study in the KSA as an initial step in order to help in clarifying the research problem issues and key elements. This study used interviews (issue focus) with selected interviewees among the health affairs of the Ministry of Saudi National Guard.

At the start of data collection, the participants received a description of the purpose of the study. All the participants approved audio taping and transcription, which produced a total of 675 minutes of speech and over 232 pages of transcripts. The interviews were first conducted in Arabic, and then the interviews were transcribed and translated into English.

The fieldwork of the first stage of the study consisted of nine semi-structured interviews with participants from different job/position levels to elicit their beliefs and experiences. The major advantage of using semistructured (face to face) interviewing according to Fontana et al., (1998) is that it provides a suitable channel for collaborating with participants, whilst letting them reveal their opinions about an issue. In addition, it was chosen for this study because it allows a better understanding of the factors that the participants believe play a key role in shaping the current situation. According to Klein (1996, p. 33) "one of the chief advantages of face-to-face communication is the ability of the participants to pick up nonverbal cues as the interaction unfolds".

During the second stage of the study, a second series of personal interviews was held between December 2015 and January 2016. The interviewees were asked to take part in refining the factors that emerged. Sixteen interviews were conducted with participants of different ranks than those in the first series. Semi-structured interviews (issue focus) were retained and the interviews were preceded, as before, by a description of the purpose of the study. The researcher also took field notes during the interviews to record any new ideas. Before this new data collection, the participants agreed to have their interviews audio recorded and transcribed, producing approximately 832 minutes of speech and over 293 pages of transcripts. The data were analysed on an interview-by-interview basis. The open coding process took account of the transcript analyses line by line, word by word, and paragraph by paragraph. Crossinterview surveys then considered and compared data to identify which factors had emerged from the other interviews. In the final analysis of the findings, they were compared with those in the current literature. Constant comparisons with the literature and the collected data as well as the iterative steps of data collecting from the participants was carried out (Goulding, 2009).

The sample of the study is the health affairs of the Ministry of the National Guard in KSA. The National Guard Health Affairs (NGHA) is one of the largest health organisations in the Kingdom, providing modern medical care to the employees of the National Guard and their families, as well as to Saudi nationals with tertiary health problems (Ministry of National Guard/Health Affairs, 2016). NGHA has also become well known internationally, especially with regard to the successful separation of conjoined twins; this is only one example of many high level services that have put NGHA at the heart of medicine in its own land (Geneva Health International Limited, 2016).

\section{Results}

This level of data collection aimed to build an initial understanding of the context of the project and hence, address the critical factors 
and aspects that might influence leadership performance improvement in the healthcare sector in Saudi Arabia. As a first step, the study asked what factors encourage or inhibit performance improvement in general. However, these aspects tend to employ different behaviours and aspects of a leader's cognitive, interpersonal qualities. All these qualities play a key role in a leader's abilities either to inhibit or encourage the performance of the organisation to improve. The dominance of factors, such as fairness and equality, the national culture and Islamic values seems to most affect leaders' decisions. It also determines their relationships with subordinates as well as their commitment to the organisation, as shown in Figure 2. Furthermore, the collected data indicated aspects that are essential in shaping the relationship between leaders and their employees. These aspects are collaboration, arrangement, communication skills and appreciation.

71 aspects had emerged in different occurrences as shown in Figure 2 below. These aspects are playing a key role in inhabiting and enabler the leadership performance in healthcare sector in the KSA. The findings show that the aspect called 'Islamic values' is the most influential element in the performance of leaders and employees in an organisation, with the high frequency of 39, as shown in Figure 2.

In addition, the current data highlight the fact that Islamic values affect the relationship between leaders and their subordinates and also their relationship with their organisation's environment. For example, one interviewee said, "Well, first it was a religious duty... no matter what our ranks are, I should observe him as a brother or a son because he is a part of this society and if I can fix things for him, it will lead to more positive results".

The second most influential factor that appeared in these data was 'fairness and equality', with a frequency of 37 . An example of this frequent perception comes from one interviewee: "For me, the features of leadership are fairness and equality...along with brotherly treatment. Such things-I believe-are essential for leadership". He added, "Of course the most significant thing I wish all leaders would have is ... fairness. [It] is very important...it is the basis of judgment, once it is applied and handled in the best way between leaders and their followers...I find this crucial point to be essential with a very positive effect on the leader's role, work and responsibilities". Similarly, one of the interviewees indicated nepotism as an example of the lack of justice that can negatively affected the process of choosing the appropriate people. In this she said, "I mean, there is nepotism and bias. Some people do not deserve to be managers. [Filling] these positions must follow certain criteria like proposing a committee to determine the qualified people".

The results of this study clearly point to the impact of the 'national culture' on leadership performance and the organisational culture and their effects on employees' job satisfaction and commitment. The frequency of this factor was 28, as shown in Figure 2. Furthermore, the study indicates that the participants, on the whole, demonstrated that emotional intelligence, such as being human and showing honesty, initiative, cognitive skill and eagerness to develop also play a crucial part in the performance of the organisation. Surprisingly, only a minority of participants indicated the importance of factors such as strategic thinking and sharing in decision-making.

The main common factors among the findings were 'Combining human aspects with regulation', 'Fairness of the evaluation criteria', 'National culture difficulties', 'Openly communicating', 'Personal relationships', 'Personifying the work environment' and 'Tolerance'. The effects of these factors on performance, as shown in Figure 2, were different in intensity, scoring between 21 and 37. Other findings show how the relations between leaders and their employees can be affected negatively as a result of a decision taken by a leader that 
affects subordinates. In this regard, an interviewee said: "I then asked him why he took it personally...he answered that he didn't and that, even though he had done wrong, my punishment was cruel...though I only applied what the system says. So sometimes, when you treat your followers well, they treat you well... But if they repeat a mistake and you have tried many times to correct them with no hope of change...when you apply the regulation and penalty, they take it personally. This behaviour has been seen many times, but after all...regulations and policies should be applied to all of us".

The study suggested that the relations between leaders and their followers need to be under the official supervision of the highest tiers of management. As number of interviewees suggested, this can provide a clear security system for both leaders and employees and protect their rights in the organisation. As one interviewee said, "Certainly, there should be something to protect and defend the employee if (sic) is right. There should be an agency to investigate the case in which an employee's evaluation is $99 \%$ and $\mathrm{s} / \mathrm{he}$ does not get promoted".

'Appreciation' emerges significantly often in this study (21 appearances) as an essential factor for motivating employees. About this, an interviewee said: "Appreciation is so important. One of the motivators that you must use (and this one I'm not really good at) is having a good memory for names". He added: "When you pass by an employee and you don't even know who he is, he will give you a strange look, but if you approach him and call him by name and ask him "How are you today? ...". In line with this, one of the participants pointed out, "Motivating words like "thank you" and "I appreciate your efforts" can affect a lot. I insist on the importance of appreciation and motivation, which makes a positive energy".

One of the more noticeable findings to emerge from this study is the power of several factors which particularly affect performance in the healthcare sector of KSA; for example, help for some employees who has personal problems, Individualising employees' motivation, having moral criteria for employment, observing according to evaluation indicators, supervising the relations between managers and employees in the workplace and evaluating employees' mindset. 'Personifying the work environment' is another finding has revealed from this study, which shows how the relations between leaders and their employees can be affected negatively as a result of a decision that is taken by a leader which affects subordinates. 


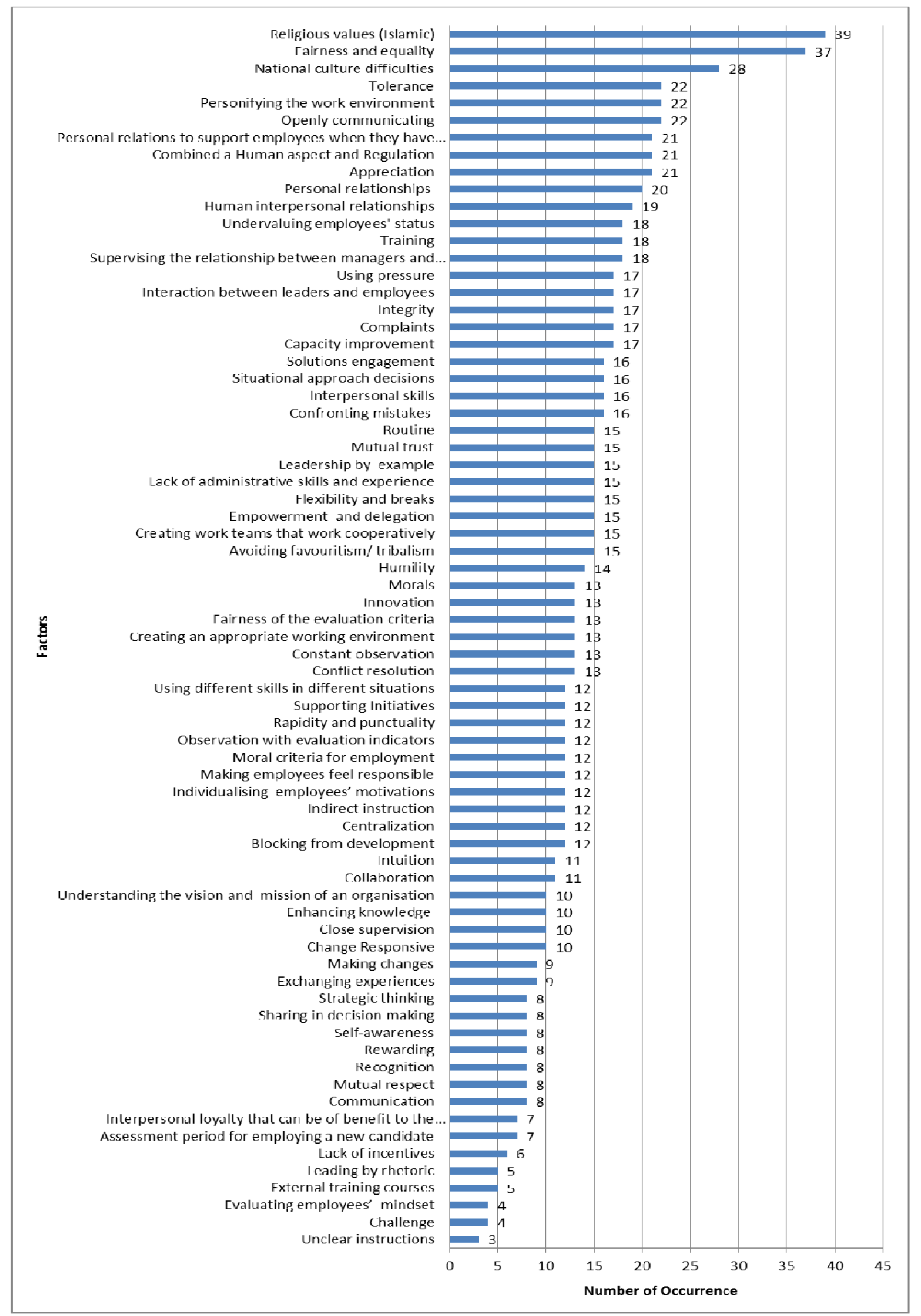

Figure 2: The most influential elements in the current situation

Namshan A Algarni, McLaughlin Patrick, Al-Ashaab Ahmed and Rashid Hamad (2018), The Journal of Organizational Management Studies, DOI: 10.5171/2018.683208 
Table 3 below displays the greater 24 factors that obtained from the analysis of the data and the frequency of their occurrence as well as the descriptions. These factors represent 30 per cent of the overall factors. These factors tend to be seen in the behaviours and aspects of the cognitive and interpersonal qualities of leaders. The study found that, a number of elements emerged as essential in shaping the aspects of workforce performance, such as Islamic values, fairness and equality and the national culture.

Table 3: The emerged factors and their descriptions

\begin{tabular}{|c|c|c|c|}
\hline Factor & & Description & Frequency \\
\hline 1. & Religious values (Islamic) & $\begin{array}{l}\text { Religious values and beliefs that influence } \\
\text { leadership thoughts, employee relationships } \\
\text { within an organisation. }\end{array}$ & 39 \\
\hline 2. & Fairness and equality & $\begin{array}{l}\text { Ensuring impartial, or non-selective management } \\
\text { of employees, but rather conforming to laid down } \\
\text { organisational rules and policies. }\end{array}$ & 37 \\
\hline 3. & National culture & $\begin{array}{l}\text { Specific aspects of national culture which } \\
\text { potentially affect performance improvement } \\
\text { within the organization. }\end{array}$ & 28 \\
\hline 4. & Tolerance (Humility) & $\begin{array}{l}\text { Broad-mindedness to employee mistakes, } \\
\text { misbehaviours, and criticisms, allowing for } \\
\text { gradual learning and improvements. }\end{array}$ & 22 \\
\hline & $\begin{array}{l}\text { Personifying the work } \\
\text { environment } \\
\text { (relationship between a } \\
\text { leader and the member of } \\
\text { their team-work) }\end{array}$ & $\begin{array}{l}\text { Kind of conflicts that potentially happens } \\
\text { between leaders and their employees as a result } \\
\text { of discussing any mistakes which related to the } \\
\text { workplace. }\end{array}$ & 22 \\
\hline 6. & Openly communicating & $\begin{array}{l}\text { Enabling direct and unrestricted exchange of } \\
\text { messages or information between leaders and } \\
\text { followers within an organizational structure. }\end{array}$ & 22 \\
\hline & $\begin{array}{l}\text { Personal relations with } \\
\text { employees to help } \\
\text { support their personal } \\
\text { issues (promotion, } \\
\text { training) }\end{array}$ & $\begin{array}{l}\text { Some employees keen on building personal } \\
\text { relations with leaders as strategy towards easily } \\
\text { attaining self-gains (promotions, external } \\
\text { training, and other incentives) within the } \\
\text { organisation. }\end{array}$ & 21 \\
\hline & $\begin{array}{l}\text { Combined a human } \\
\text { aspect and regulation }\end{array}$ & $\begin{array}{l}\text { Perceived concurrent application of both social } \\
\text { (human) and rule-based approaches could yield } \\
\text { better employee output. }\end{array}$ & 21 \\
\hline
\end{tabular}

Namshan A Algarni, McLaughlin Patrick, Al-Ashaab Ahmed and Rashid Hamad (2018), The Journal of Organizational Management Studies, DOI: 10.5171/2018.683208 


\begin{tabular}{|c|c|c|}
\hline $\begin{array}{l}\text { 9. Appreciation } \\
\text { (recognition) }\end{array}$ & $\begin{array}{l}\text { Acknowledging and according value to employee } \\
\text { attributes, and (or) outputs. }\end{array}$ & 21 \\
\hline 10. Personal relationships & $\begin{array}{l}\text { Building good interpersonal relationships with, } \\
\text { and among employees is key to improving } \\
\text { performance, and achieving a conducive working } \\
\text { environment. }\end{array}$ & 20 \\
\hline $\begin{array}{l}\text { 11. Human interpersonal } \\
\text { relationships }\end{array}$ & $\begin{array}{l}\text { Improving performance through building a good } \\
\text { human interpersonal relationship among } \\
\text { employees for a more friendly, and motivated } \\
\text { workplace. }\end{array}$ & 19 \\
\hline $\begin{array}{l}\text { 12. Undervaluing employees' } \\
\text { status }\end{array}$ & $\begin{array}{l}\text { Underrating and failing to appreciate the } \\
\text { importance of employees in an organisation, } \\
\text { likely to yield negative performance and outputs }\end{array}$ & 18 \\
\hline 13. Training & $\begin{array}{l}\text { Sequence courses and activities imported into } \\
\text { employees to build their knowledge, skills and } \\
\text { competence for undertaking organisational roles } \\
\text { and responsibilities. }\end{array}$ & 18 \\
\hline $\begin{array}{l}\text { 14. Supervising the } \\
\text { relationship between } \\
\text { managers and employees } \\
\text { in the workplace }\end{array}$ & $\begin{array}{l}\text { A formal approved duty of a designated } \\
\text { department in the organization, which will } \\
\text { involve observing, assess, and manages the } \\
\text { relationship between both sides to avoid } \\
\text { relational frictions capable of affecting normal } \\
\text { work within the work environment. }\end{array}$ & 18 \\
\hline 15. Applying Pressure & $\begin{array}{l}\text { Exerting stressful requirements on employees as } \\
\text { a second resort to solving problems, could } \\
\text { sometimes bring about good results. }\end{array}$ & 17 \\
\hline $\begin{array}{l}\text { 16. Interaction between } \\
\text { leaders and employees }\end{array}$ & $\begin{array}{l}\text { Mutual relations and interfacing between leaders } \\
\text { and their subordinates within the organization. }\end{array}$ & 17 \\
\hline 17. Integrity & $\begin{array}{l}\text { The quality of being honest, upright, and reliable. } \\
\text { Having strong moral principles }\end{array}$ & 17 \\
\hline 18. Complaints & $\begin{array}{l}\text { Complaints within organizations are inherent } \\
\text { and critical, and should be treated with } \\
\text { expedition in every work environment. }\end{array}$ & 17 \\
\hline 19. Capacity improvement & $\begin{array}{l}\text { Employee capacity Improvement through } \\
\text { training and education for knowledge and skills. }\end{array}$ & 17 \\
\hline 20. Solutions engagement & $\begin{array}{l}\text { Being part of solution efforts to potential } \\
\text { problems within the workplace. }\end{array}$ & 16 \\
\hline
\end{tabular}

Namshan A Algarni, McLaughlin Patrick, Al-Ashaab Ahmed and Rashid Hamad (2018), The Journal of Organizational Management Studies, DOI: 10.5171/2018.683208 


\begin{tabular}{|c|c|c|}
\hline $\begin{array}{l}\text { 21. Situational approach } \\
\text { decisions }\end{array}$ & $\begin{array}{l}\text { Leadership decisions depending on situation and } \\
\text { personal dispositions. }\end{array}$ & 16 \\
\hline 22. Interpersonal skills & $\begin{array}{l}\text { Leadership personal ability to relate easily and } \\
\text { liberally, helping them manage their work while } \\
\text { builds relationship with employees. }\end{array}$ & 16 \\
\hline $\begin{array}{l}\text { 23. Moral criteria for } \\
\text { employment in health } \\
\text { sector }\end{array}$ & $\begin{array}{l}\text { Part of the criteria for employment should } \\
\text { include the human aspect of sound moral values, } \\
\text { in balance with other requirements. }\end{array}$ & 12 \\
\hline $\begin{array}{l}\text { 24. Evaluating the } \\
\text { employees' mind-set }\end{array}$ & $\begin{array}{l}\text { Ascertaining employees' willingness to work, or } \\
\text { desire for self-development through the } \\
\text { continual delegation of tasks and observance of } \\
\text { reactions. }\end{array}$ & 4 \\
\hline
\end{tabular}

The study findings corresponds with Bolden and Gosling (2006) who propose that leadership benefits by sets of components, such as the traits, qualities, skills, and behaviours which encourage the teamwork, development and commitment of others in an organisational environment. (Bass and Riggio, 2006) emphasises the importance of 'fairness and equality' within the successful organizations environment.

While the data shown that only two of the participants believed the effect of 'Strategic thinking' on their performance, (Bass and Avolio, 1993) indicated to the important role of this factor and argue that "strategic thinking helps to create and build the vision of an agency's future" (p. 119). The literature also indicated certain other factors that do not appear in the field study findings, such as having public abilities and skills, matching job needs with employees' capability or talent and technical competence (Boyatzis \& Boyatzis, 2008; Yukl, 2006; Hollenbeck, et al., 2006; Bass, 1990 and Riggo, 2006).

\section{Discussion}

This exploratory study was designed to determine the effect of leadership style and practices on the job performance of leaders in Saudi Arabia's healthcare sector.

A case study approach was chosen to conduct this exploratory study. According to Yin (2013, p. 14) a "distinctive need for case study research arises out of the desire to understand complex social phenomena". This research was intended to study social phenomena that aimed to reveal something about leadership competencies and how they may help to facilitate a culture of leadership performance development in healthcare organisations. The interpretive paradigm and GT were useful for this research as they enable the researcher to explore, explain and describe "what is going on" based mainly on individuals' perceptions and meanings, and offer the ability to construct a theory that is grounded in the data collected (Corbin and Strauss, 1994). Hence, this study used a constructive-interpretive philosophical approach, applying a qualitative strategy to answer its questions and achieve the objectives of the research.

The findings suggest 71 factors that can inhabit and enable improvement of performance. These factors tend to be seen in the behaviours and aspects of the cognitive and interpersonal qualities. A number of elements emerged as important in shaping

Namshan A Algarni, McLaughlin Patrick, Al-Ashaab Ahmed and Rashid Hamad (2018), The Journal of Organizational Management Studies, DOI: 10.5171/2018.683208 
the development of performance, such as Islamic values, fairness and equality and the national culture. The study shows that aspect 'Islamic values' is the most influential element in the performance of leaders and employees in an organisation. The concept of the Islamic work ethic (IWE) has its basis from the Quran and the sayings of Prophet Mohammed.

The results that individuals in field study investigated are highly committed to the Islamic work values are consistent with previous research (Rees and Althakhri, 2008; Yousef, 2000,2001; Ali, 1987; Mellahi, 2007). Associating the findings of this study with those other studies, Hunt and At-Twaijri (1996) indicated that the Islamic work ethic plays a fundamental role in the commitment of Saudi leaders toward their organisational tasks and with their subordinates. In a previous study, Yousef (2001) pointed out that Islamic work ethic has an strong influence on both committed to organisation and satisfied with the job. Additionally, Ali (1987) indicated in his study to the Islam as one of the most influential factors which have shaped Arab value systems.

The findings of this study revealed that the influence of 'national culture' and organisational culture. Similarly, Yousef (2001) indicated to that the significant role of national culture to shape an individual's work ethic. Culture has been defined to imply a set of shared, taken-for-granted implicit assumptions held by the members of an organisation, which determines the way that they perceive, think about and respond to things (Schein, 1996). In addition, Hunt and At-Twaijri (1996) claim that further aspects such as friendships and personal thoughts have given more attention from Saudi managers over performance and organisational objectives. This finding is linked with Garrido-Franco et al., (2002) who argued that cultural physiognomies can the influence organisational structure decisionmaking processes within organizations. Similarly, Idris (2007) investigated the influence of cultural barriers on the organizational performance in Saudi Arabia (p. 36) "Executives and managers in Saudi Arabia face great challenges in their endeavour to improve the performance of their organizations". These particularly, cultural issues and work practices that limit employee performance levels compared with those in developed international companies (Idris, 2007). According to Bass and Avolio, (1993, p. 113) "culture can affect how decisions are made with respect to such areas as recruitment, selection, and placement within the organization". Similarly, it is believed that there are two main strands that shape Saudi Arabian culture; firstly, tribal traditions, customs and values, and secondly, Islamic culture. Saudi culture is therefore a blend of both (AlGhamdi, 2012).

This study found that the domination of fairness and equality, which appears among the factors that most affect leaders' decisions; it also determines their relations with subordinates as well as their commitment to the organisation. The results in line with Bass and Avolio (1994) who indicated to the 'transformational leadership' characteristics with the application of certain values to create effective leadership is one of the deeply-held beliefs of leaders; these values include areas such as justice and integrity (Yukl, 2002). Similarly, Armit et al, (2015), state that leaders should emphasise fairness and honesty in their dealings with all, challenging unethical practices or social injustices on behalf of all, not only their followers. This in line with Sanghi, (2016) who stress that fairness and equality aspects should be given a high priority from leaders in the workplace.

Such these factors tend to be seen from the behaviours and aspects of cognitive, interpersonal qualities of leaders. The aspects all play a key role in a leader's abilities either to inhibit or enable their own performance improvement and the performance of the workforce. The participants on the whole demonstrated that emotional intelligence, such as "being human", honesty, initiative, cognitive skill 
and eagerness to develop play crucial parts as well.

Communication within the organisation appeared as one of the aspects that heavily influences organisation performance and shapes the relationship between its members, as shown in Table 2. In line with this finding, Bratton and Gold (2012) stress that the effectiveness of communication can be affected by various organisational characteristics, such as organisation hierarchy, power relations and the abilities and biases of managers and non-mangers across the organisation's departments and levels (Bratton and Gold, 2012). In his book, Yukl (2002) also finds that attention should be paid to delegating authority to staff and improving communication channels between managers and staff. Furthermore, previous studies indicate to the key role of empowerment by management to enhance the employees' participation, productivity, satisfaction and commitment (Conger \& Kanungo 1988; Malone, 1997; Lok \& Crawford 2004 ). 'Appreciation' has significantly emerged from this study as an essential factor for motivating employees. This result consistent with (Yukl, 2002 and Christopher, 2013).

Whilst the data show that only two of the participants believed in the effect of 'strategic thinking' on their performance, authors like Bass and Avolio (1994) indicate the important role of this factor and argue that "strategic thinking helps to create and build the vision of an agency's future". Similarly, Sanghi (2016) reinforces that behavioural strategic thinking should involve a course of action to accomplish a long-term goal and shares with others one's personal view of the desirable future state of the organisation.

These results suggest that these new areas where further research would be interesting to be investigated in the future. Specifically, interesting topics for future cross cultural research. McAlearney (2006, p. 968) indicates to the important role of management in healthcare organizations, stating that "In healthcare settings, there is often little attention given to how improve management practice, increasing the likelihood that previous mistakes will be repeated". Moreover, the literature demonstrates that the current practice of planning and developing strategies in the health sector is one-sided and only from the top, justifying the view that the KSA needs to correct the direction of its health reforms (Al-Borie and Abdullah, 2013).

\section{Conclusions and Implications}

Taken together, these results suggest that there is broad agreement between the study findings and the literature in the vast majority of factors. However, one of the more significant findings to emerge from this study is that a number of factors that particularly affect leadership performance in the public health sector of KSA are dominant. Examples include personal relations with some employees as a form of personal support, individualising employees' motivation, having moral criteria for employment, observing using evaluation indicators, supervising the relationship between managers and employees in the workplace and evaluating employees' mind-set. Reviewing the literature did not show the importance of any of these factors for leadership competency and still less for leadership performance as a whole. However, this result suggests that it would be interesting in future studies to investigate the influence of these factors on leadership performance improvement extensively in healthcare sector. Additionally, this research fulfils an identified need to study how culture aspects can influence workforce practices in healthcare organisations in the KSA and to what extent can that affect the quality of services delivered to the patients.

The findings of this study suggest that the relations between leaders and their followers need to be under the official supervision of the highest tiers of management. As a number of interviewees suggested, this can provide a clear security system for both leaders and employees and protect their 
rights in the organisation. As one interviewee said, "Certainly, there should be something to protect and defend the employee if [he] is right. There should be an agency to investigate a case in which an employee's evaluation is $99 \%$ and $\mathrm{s} /$ he does not get promoted". Importantly, there are several factors in the findings of the present study that demonstrate effects on leadership performance that are not shown to be important in the literature. Among them are helping employees with support in personal problems, individualising their motivation, having moral criteria for employment, supervising the relationship between managers and employees in the workplace and evaluating the employees' mind-set. This presents an important issue for future research.

Because of the chosen research approach, the research results may lack generalisability. Therefore, researchers are encouraged to test the proposed propositions further.

\section{References}

1. Abdulaziz Al-Bosaily, Glenn Lovell, Alain Sfeir, Ben Cowling, Joycia Young, Dino Wilkinson, Sara Khoja, Susie Abdel-Nabi and Niall O'Toole (2017) Growth opportunities in Saudi Arabia. Riyadh .

2. Al-Rabeeah, A. (2003) 'The history of health care in the Kingdom of Saudi Arabia with emphasis on pediatric surgery.', Saudi medical journal, 24 Suppl, pp. S9-10.

3. Al-Yousuf, M., Akerele, T. M. and AlMazrou, Y. Y. (2002) 'Organization of the Saudi health system.', Eastern Mediterranean health journal $=$ La revue de sante de la Mediterranee orientale $=$ al-Majallah alsihhiyah li-sharq al-mutawassit, 8(4-5), pp. 645-53.

4. Alexander, N. H. (2011) 'Teaching Leadership to Female Students in Saudi Arabia', Advancing Women in Leadership, 31(0), pp. 199-212.
5. Ali, A. (1987) 'Value Systems as Predictors of Work Satisfactions of Arab Executives', International Journal of Manpower, 8(2), pp. 3-6.

6. Alkhamis, A., Cosgrove, P., Mohamed, G. and Hassan, A. (2017) 'The personal and workplace characteristics of uninsured expatriate males in Saudi Arabia.', BMC health services research, 17(1), p. 56.

7. Almalki, M., FitzGerald, G. and Clark, M. (2011) 'Health care system in Saudi Arabia: an overview'.

8. AM Idris (2007) 'Cultural barriers to improved organizational performance in Saudi Arabia', S.A.M. Advanced Management Journal, 72(2), p. 36.

9. Bass, B. and Avolio, B. (1994) 'Transformational leadership and organizational culture', The International Journal of Public Administration. Edited by B. A. Bernard Bass. Taylor \& Francis, 17(3-4), pp. 541-554.

10.Bass, B. M. and Riggio, R. E. (2006) Transformational leadership. Psychology Press.

11.BERNARD M. BASS and BRUCE J. AVOLIO (1993) 'TRANSFORMATIONAL LEADERSHIP AND ORGANIZATIONAL CULTURE.: SearchPoint for Cranfield University', Public Administration Quarterly, 17(1), pp. 112-121.

12.Binder, M. and Edwards, J. S. (2010) 'Using grounded theory method for theory building in operations management research: a study on inter-firm relationship governance', International Journal of Operations \& Production Management. Emerald Group Publishing Limited, 30(3), pp. 232-259.

13.Bolden, R. and Gosling, J. (2006) 'Leadership competencies: time to change the tune?', Leadership. Sage Publications, 2(2), pp. 147-163.

14.Boyatzis, R. and Boyatzis, R. E. (2008)

Namshan A Algarni, McLaughlin Patrick, Al-Ashaab Ahmed and Rashid Hamad (2018), The Journal of Organizational Management Studies, DOI: 10.5171/2018.683208 
'Competencies in the 21st century', Journal of management development. Emerald Group Publishing Limited, 27(1), pp. 5-12.

15.Bratton, J. and Gold, J. (2012) Human Resource Management Theory and Practice. London: Palgrave Macmillan.

16.Conger, J. and Kanungo, R. (1988) 'The empowerment process: Integrating theory and practice', Academy of management review, 13(3), pp. 471-482.

17.Corbin, J. M. and Strauss, A. L. (2014) Basics of qualitative research: techniques and procedures for developing grounded theory. California: SAGE.

18.Corbin, J. and Strauss, A. (1994) Grounded theory methodology, Handbook of qualitative research. Edited by L. Denzin, Norman K, Yvonna. London: SAGE Publications.

19.Department, of, Economic, and, Social and Affairs - United Nations publication (2003) The global situation of young people. New York.

20.Dirani, K. M., Hamie, C. S. and Tlaiss, H. (2017) 'Leadership in Saudi Arabia: A Multifaceted Phenomenon', in Leadership Development in Emerging Market Economies. New York: Palgrave Macmillan US, pp. 245260. doi: 10.1057/978-1-137-58003-0_14.

21.Fontana, A., Frey, J. H., Denzin, N. K. and Lincoln, Y. S. (1998) 'Collecting and interpreting qualitative materials', Interviewing: The art of science, pp. 47-78.

22.Franco, L. M., Bennett, S. and Kanfer, R. (2002) 'Health sector reform and public sector health worker motivation: a conceptual framework', Social Science \& Medicine, 54(8), pp. 1255-1266.

23.Garrido-Franco, M., Ehlert, $\quad$ S., Messerschmidt, A., Marinkovic', S., Huber, R., Laber, B., Bourenkov, G. P. and Clausen, T. (2002) 'Structure and function of threonine synthase from yeast.', The Journal of biological chemistry, 277(14), pp. $12396-$ 405.

24.Geneva Health International Limited (2016) National Guard Health Affairs. Available at: http://www.genevahealthmiddleeast.com/S audi-Arabia/Why-Saudi-Arabia/Our-Clients.

25.Glaser, B. G., Strauss, A. L. and Strutzel, E. (1968) The discovery of grounded theory; strategies for qualitative research, Nursing research. LWW.

26.Goulding, C. (2009) Grounded theory perspectives in organizational research, The Sage handbook of organizational research. New Deldhi.

27.Hamdan, A. (2005) 'Women and Education in Saudi Arabia: Challenges and Achievements.', International Education Journal. ERIC, 6(1), pp. 42-64.

28. Hamed, A., Saleh, H. and Alabri, S. (2013) 'USING NVIVO FOR DATA ANALYSIS IN QUALITATIVE RESEARCH', International Interdisciplinary Journal of Education -, 2(2).

29.Hunt, D. M. and At-Twaijri, M. (1996) 'Values and the Saudi manager: an empirical investigation', Journal of Management, 15(5), pp. 48-55.

30.Khaliq, A. (2012) 'The Saudi Healthcare System: A View from the Minaret', World Health \& Population, 13(3), pp. 52-64.

31. Kirsten Armit, Dr Lola Loewenthal, Dr Regina Eckert, Thomas West, A. L. (2015) Leadership and leadership development in health care, TheKing'sFund.

32.Klein, S. M. (1996) 'A management communication strategy for change', Journal of Organizational Change Management, 9(2), pp. 32-46.

33. Malone, T. (1997) 'Is empowerment just a fad? Control, decision making, and IT', MIT Sloan Management Review, 38(2), pp. 23-35. 
34.McAlearney, A. S. (2006) 'Leadership development in healthcare: a qualitative study', Journal of Organizational Behavior. Wiley Online Library, 27(7), pp. 967-982.

35.Mellahi, K. (2007) 'The effect of regulations on HRM: private sector firms in Saudi Arabia', The International Journal of Human Resource Management. Taylor \& Francis, 18(1), pp. 85-99.

36. Ministry of National Guard/Health Affairs (2016) Ministry of National Guard/Health Affairs. Available at: http://new.ngha.med.sa/English/Pages/defa ult.aspx (Accessed: 22 March 2016).

37.Mohammed Al-Borie, $\mathrm{H}$. and Tanweer Abdullah, M. (2013) 'A "DIRE" needs orientation to Saudi health services leadership', Leadership in Health Services, 26(1), pp. 50-62.

38.PWC - Middle East - Hala Kudwah (2017) Spotlight on: Saudi Arabia's Transformation PwC Middle East Annual Report 2017, Keeping up with change in Saudi Arabia. Available at: https://www.pwc.com/m1/en/aboutus/annual-report/saudi-arabiatransformation.html.

39.Rees, C. and Althakhri, R. (2008) 'Organizational change strategies in the Arab region: A review of critical factors', Journal of Business Economics and ....

40.Sackmann, S. A. (1991) 'Uncovering culture in organizations', The Journal of applied behavioral science, 27(3), pp. 295317.

41.Saleh, A. and Otaibi, A. (2017) 'An Overview of Health Care System in Saudi Arabia', International Journal of Management and Administrative Sciences International Journal of Management and Administrative Sciences (IJMAS), 4(12), pp. 1-12. Available at: www.ijmas.org.

42.Sanghi, S. (2016) The handbook of competency mapping: understanding, designing and implementing competency models in organizations. New York: SAGE Publications Pvt. Ltd.

43.Sanghi, S. (2016) The Handbook of Competency Mapping: Understanding, Designing and Implementing Competency Models in Organizations. London: SAGE Publications.

44.Saudi Embassy in the USA (2017) SAUDI ARABIA: POLITICAL, ECONOMIC \&amp; SOCIAL DEVELOPMENT. WASHNGTON.

45.Saudi General Authority Statistics (no date) General Statistics of Saudi Arbia. Available at: http://www.stats.gov.sa/en.

46.Schein, E. H. (1996) 'Culture: The Missing Concept in Organization Studies', Administrative Science Quarterly. Washington, DC): Sage Publications, Inc.Johnson Gradua, 41(2), p. 229.

47.Schein, E. H. (2004) 'Organizational Culture and Leadership', Leadership, 7, p. 437.

48.Stephen Walston, a, Yousef Al-Harbi, b and Badran Al-Omarc (2008) 'The changing face of healthcare in Saudi Arabia'.

49.The Saudi General Authority For Statistics (2017) Surveys Demographic Survey 2016. Riaydh.

50.Walston, S., Al-Harbi, Y. and Al-Omar, B. (2008) 'The changing face of healthcare in Saudi Arabia', Annals of Saudi medicine. Riyadh: King Faisal specialist Hospital, 28(4), pp. 243-50.

51.Yin, R. K. (1989) Case study research: design and methods. London: SAGE Publications.

52.Yin, R. K. (2013) Case study research: design and methods. London: SAGE Publications.

53.Yousef, D. (2000) 'Organizational 
commitment: A mediator of the relationships of leadership behavior with job satisfaction and performance in a non-western country', Journal of Managerial Psychology, 15(1), pp. 6-24.

54.Yousef, D. A. (2001) 'Islamic work ethic A moderator between organizational commitment and job satisfaction in a cross-cultural context', Personnel Review,
30(2), pp. 152-169.

55.Yukl, G. (2002) Leadership in organizations. Michigan: Prentice Hall.

56.Yusuf, N. (2014) 'Private and public healthcare in Saudi Arabia: future challenges', International Journal of Business and Economic Development, 2(1). 